\author{
Marquette University \\ e-Publications@Marquette
}

8-2009

\title{
Does organic modification of layered double hydroxides improve the fire performance of PMMA?
}

Calistor Nyambo

Marquette University

Dan Chen

Hunan Normal University

Shengpei Shu

Hunan Normal University

Charles A. Wilkie

Marquette University, charles.wilkie@marquette.edu

Follow this and additional works at: https://epublications.marquette.edu/chem_fac

Part of the Chemistry Commons

\section{Recommended Citation}

Nyambo, Calistor; Chen, Dan; Shu, Shengpei; and Wilkie, Charles A., "Does organic modification of layered double hydroxides improve the fire performance of PMMA?" (2009). Chemistry Faculty Research and Publications. 94.

https://epublications.marquette.edu/chem_fac/94 
Marquette University

\section{e-Publications@Marquette}

\section{Chemistry Faculty Research and Publications/College of Arts and Science}

This paper is NOT THE PUBLISHED VERSION; but the author's final, peer-reviewed manuscript. The published version may be accessed by following the link in the citation below.

Polymer Degradation and Stability, Vol. 94, No. 8 (August, 2009): 1298-1306. DOI. This article is (C) Elsevier and permission has been granted for this version to appear in $\underline{\mathrm{e}}-$ Publications@Marquette. Elsevier does not grant permission for this article to be further copied/distributed or hosted elsewhere without the express permission from Elsevier.

\section{Does Organic Modification of Layered Double Hydroxides Improve the Fire Performance of PMMA?}

\section{Calistor Nyambo}

Department of Chemistry and Fire Retardant Research Facility, Marquette University, Milwaukee, WI

Dan Chen

College of Chemistry and Chemical Engineering, Hunan Normal University, China

Shengpei Su

College of Chemistry and Chemical Engineering, Hunan Normal University, China

Charles A. Wilkie

Department of Chemistry and Fire Retardant Research Facility, Marquette University, Milwaukee, WI

\section{Abstract}

The effect of modified layered double hydroxides (LDHs) on fire properties of poly(methyl methacrylate) is investigated. Organically-modified LDHs were prepared via rehydration of calcined hydrotalcite in a palmitate solution. Composites consisting of the organo-LDHs, unmodified hydrotalcite and calcined 
oxides were prepared with poly(methyl methacrylate) using melt blending. Thermal and fire properties of the (nano)composites were studied. The thermogravimetric analyses of the composites show an increase in thermal stability. Fire performance, evaluated using cone calorimetry, show that organicallymodified LDHs composites give the best reductions in peak heat release rate, PHRR, i.e., $51 \%$ at $10 \%$ weight loading. Dispersion of the LDHs was characterized using transmission electron microscopy and Xray diffraction. Nanocomposite formation was observed with organically-modified LDHs, while the unmodified LDH composites gave only microcomposites.

\section{Keywords}

Layered double hydroxide; Calcination; Thermogravimetric analysis; Poly(methyl methacrylate); one calorimeter

\section{Introduction}

Layered double hydroxides ( $\mathrm{LDHs}$ ) are anionic clays with the general formula $\left.\left[\mathrm{M}^{2+}{ }_{1-x} \mathrm{M}^{3+}{ }_{x}(\mathrm{OH})_{2}\right]^{\mathrm{x+}}\left(\mathrm{A}_{\mathrm{x} / \mathrm{n}}\right)^{\mathrm{n}-} \cdot \mathrm{mH}_{2} \mathrm{O}\right]$, where $\mathrm{M}^{2+}=$ divalent cation $\left(\mathrm{Mg}^{2+}, \mathrm{Zn}^{2+}, \mathrm{Ni}^{2+}, \mathrm{Cu}^{2+}\right.$, etc. $)$ and $\mathrm{M}^{3+}=$ trivalent cation $\left(\mathrm{Al}^{3+}, \mathrm{Fe}^{3+}, \mathrm{Mn}^{3+}\right.$ etc.) while $\mathrm{A}^{\mathrm{n}-}$ is the charge balancing interlayer anion. The major advantage of LDHs is that both the composition and ratio of the metals in the layers and the gallery anions can be varied. This gives LDHs highly tunable properties that makes them suitable for use in a wide range of application such as catalysts ${ }^{[1]}$, scavengers for pollutants ${ }^{[2]}$, flame

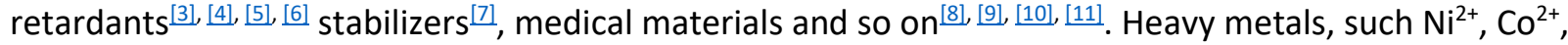
$\mathrm{Cr}^{3+}, \mathrm{Ga}^{3+}$, may be used to make LDH nanocomposites, but these metals have potential toxicity to the environment while the combination of $\mathrm{Mg}^{2+}$ and $\mathrm{Al}^{3+}$ is generally considered environmentally friendly.

The naturally occurring-LDH is hydrotalcite, which consists of $\mathrm{Mg}^{2+}$ and $\mathrm{Al}^{3+}$ layers intercalated with a carbonate anion, described by the formula $\mathrm{Mg}_{6} \mathrm{Al}_{2}(\mathrm{OH})_{16} \mathrm{CO}_{3} \cdot 4 \mathrm{H}_{2} \mathrm{O}$. Its structure is closely related to that of the mineral brucite, $\mathrm{Mg}(\mathrm{OH})_{2}$, in which $\mathrm{Mg}^{2+}$ cations are coordinated octahedrally to hydroxyl groups in the metal layers. Isomorphous substitution of the $\mathrm{Mg}^{2+}$ with $\mathrm{Al}^{3+}$ creates a net positive charge on the layers, which is counter balanced by the carbonate anions ${ }^{[12]}$. Calcining hydrotalcite at around $450{ }^{\circ} \mathrm{C}$ yields a mixture of oxides that can be reconstructed back to the parent LDH by rehydration in an aqueous solution of the charge balancing anion $\frac{[13]}{}$. This unique property of LDHs has been referred to as the "memory effect" and provides an effective route to intercalate organic anions in the galleries of the layered double hydroxides. The calcination and rehydration conditions - temperature, heating rate, $\mathrm{pH}$ and time - are important variables that affect the success of rehydration process $\frac{[14]}{\text {, } 15]}$. For example, a very high heating rate may result in rapid elimination of carbon dioxide and water from the LDH and this may disrupt the layered structure of the calcined product.

In mirror image resemblance to anionic clays are cationic clays, like montmorillonite (MMT), which have a net negative charge on the layers balanced by cations in the interlayer. Onium ions, such as long chain alkyl quaternary ammonium, $\mathrm{R}_{4} \mathrm{~N}^{+}$, are generally used to replace the $\mathrm{Na}^{+}$cations in pristine MMT so as to reduce the hydrophilicity of the clay, making it compatible with polymer. The use of organicallymodified MMT to make nanocomposites has been studied extensively and is well understood [16], [17], [18], [19]. It is generally accepted that outstanding fire properties of MMT are only achieved when the clay is organically-modified resulting in nano-dispersion of the clay in polymer i.e., nanocomposite formation [20], [21]. Unmodified MMT is highly polar inorganic material that is incompatible and difficult to disperse in polymers. When dispersed in a polymer by either melt or solution blending, 
the unmodified clay often agglomerates and forms microcomposites which are associated with poor fire properties. The similarity of anionic clays (LDHs) to modified and unmodified MMT has not been tested and is the subject of this study.

In this paper we study the effect on the fire performance of both unmodified and organically-modified LDHs in poly (methyl methacrylate) composites. Comparing the methods of preparing LDHs, i.e., coprecipitation, anion exchange, calcination and rehydration, on the fire performance is also an objective of this work. This study should be useful in understanding the importance of the layered structure of the LDH as it will also compare the fire performance of calcined oxides to those of both modified and unmodified layered double hydroxides.

\section{Experimental}

\subsection{Materials}

The materials, poly(methyl methacrylate) $(\mathrm{PMMA})\left(M_{\mathrm{w}}=120,000\right)$, sodium hydroxide flakes, magnesium nitrate hexahydrate, $\mathrm{Mg}\left(\mathrm{NO}_{3}\right)_{2} \cdot 6 \mathrm{H}_{2} \mathrm{O}$, aluminum nitrate nonahydrate, $\mathrm{Al}\left(\mathrm{NO}_{3}\right)_{3} \cdot 9 \mathrm{H}_{2} \mathrm{O}$, and sodium nitrate, were acquired from Aldrich Chemical Co. Palmitic acid $\left(\mathrm{CH}_{3}\left(\mathrm{CH}_{2}\right)_{14} \mathrm{COOH}\right)(95 \%)$, was obtained from $\mathrm{TCl}$ and methanol (MeOH) from Alfa Aesar. Hydrotalcite, pural $\mathrm{MG} 63 \mathrm{HT}$, referred herein as $\mathrm{MgAl}$-carbonate $\mathrm{LDHs}$, was kindly provided by Sasol Germany $\mathrm{GmbH}$. These materials were used as received without further purification.

\subsection{Instrumentation}

Powder X-ray diffraction measurements (PXRD) and XRD for the composites were performed in a Rigaku Miniflex II Desktop X-ray diffractometer with Cu (K alpha) radiation $\lambda=1.54078 \AA$, from a sealed X-ray tube. The powder samples were prepared and mounted on a glass holder and the composites by compression molding and mounted on an aluminum sample holder. The data were collected at various $2 \vartheta$ values from 0 to $70^{\circ}$ at a scan speed of $5^{\circ}$ per minute with a sampling width of 0.02 . Basal spacing of $\mathrm{LDHs}$ and nanocomposites were obtained from the $00 /$ reflections.

Bright field transmission electron microscopy (TEM) images of the nanocomposites were obtained at $60 \mathrm{kV}$ with a JEOL 1230 electron microscope. The samples were ultramicrotomed with a diamond knife on an AO-E microtome at room temperature to give $\sim 90 \mathrm{~nm}$ thick section. The sections were then transferred from the knife-edge to Cu grids.

Fourier transform infrared spectra (FT-IR) were obtained using the $\mathrm{KBr}$ method on a Nicolet Magna-IR 560 spectrometer operating at $1 \mathrm{~cm}^{-1}$ resolution in the $400-4000 \mathrm{~cm}^{-1}$ region. Thermogravimetric analysis, (TGA) and differential thermal analysis (DTA) were performed on an SDT 2960 simultaneous DTA-TGA instrument from 50 to $800{ }^{\circ} \mathrm{C}$ at a heating rate of $20^{\circ} \mathrm{C} / \mathrm{min}$ in $\mathrm{N}_{2}$, flowing at $85 \pm 5 \mathrm{ml} / \mathrm{min}$, with sample sizes of $15.0 \pm 1.0 \mathrm{mg}$ contained in aluminum sample cups. All samples were run in triplicate and the average values are reported; temperatures are considered accurate to $\pm 3^{\circ} \mathrm{C}$ and the error on the fraction of non-volatile materials is $\pm 2 \%$. Calcination was performed in a Thermolyne 1300 furnace at $450{ }^{\circ} \mathrm{C}$ for $18 \mathrm{~h}$ for the hydrotalcite and at $1000^{\circ} \mathrm{C}$ for $24 \mathrm{~h}$ for the char obtained after cone calorimetry.

Approximately $30 \mathrm{~g}$ of PMMA composite samples was compression molded into $10 \mathrm{~cm} \times 10 \mathrm{~cm}$ square plaques of uniform thickness $(\sim 3 \mathrm{~mm})$ before cone calorimetry was performed on an Atlas Cone 2 instrument at an incident flux of $50 \mathrm{~kW} / \mathrm{m}^{2}$ with a cone shaped heater; the spark was continuous until 
the sample ignited. All samples were run in triplicate and the average value, with standard deviation, is reported; results from cone calorimeter are generally considered to be reproducible to $\pm 10 \%$.

\subsection{Preparation of magnesium-aluminum nitrate layered double hydroxide}

The magnesium-aluminum nitrate layered double hydroxide (MgAl-Nitrate LDH) was synthesized by the coprecipitation method, following a procedure similar to that reported by Meyn et al. ${ }^{[22]}$. The preparation was performed in a nitrogen atmosphere to exclude carbon dioxide whose presence will lead to the formation of a carbonate $\mathrm{LDH}$. A solution of $32.0 \mathrm{~g}$ of $\mathrm{Mg}\left(\mathrm{NO}_{3}\right)_{2} \cdot 6 \mathrm{H}_{2} \mathrm{O}(0.125 \mathrm{~mol})$ and $23.4 \mathrm{~g}$ of $\mathrm{Al}\left(\mathrm{NO}_{3}\right)_{3} \cdot 9 \mathrm{H}_{2} \mathrm{O}(0.0625 \mathrm{~mol})$ in $125 \mathrm{ml}$ of degassed and deionized water was added dropwise over $1 \mathrm{~h}$ to a solution of $12.5 \mathrm{~g}$ of $\mathrm{NaOH}(0.313 \mathrm{~mol})$ and $18.2 \mathrm{~g}$ of $\mathrm{NaNO}_{3}(0.214 \mathrm{~mol})$ in $145 \mathrm{ml}$ of degassed/deionized water. The $\mathrm{pH}$ of the solution was maintained at 10.0 by adding $1 \mathrm{M} \mathrm{NaOH}$ solution, as needed. The resulting white precipitate was aged for $24 \mathrm{~h}$ at $65^{\circ} \mathrm{C}$, and then filtered until all of the supernatant liquid was removed. The sample was washed several times with large amounts of deionized and degassed water, and then dried at $50{ }^{\circ} \mathrm{C}$ in a vacuum oven.

\subsection{Preparation of the magnesium-aluminum palmitate layered double hydroxide}

The magnesium-aluminum palmitate (MgAl-C16 LDH) was prepared by rehydration of the calcined hydrotalcite following a procedure reported by Chibwe and Jones ${ }^{[14]}$. In a typical experiment, the MgAlcarbonate LDH was calcined in air at $450 \pm 10^{\circ} \mathrm{C}$ for $18 \mathrm{~h}$. $1 \mathrm{~g}$ of the calcined material was then added to a $100 \mathrm{ml}$ of $0.1 \mathrm{M}$ palmitate solution, prepared by dissolving the palmitic acid in a warm water/methanol solution (1:1 volume ratio) containing $0.1 \mathrm{M}$ of $\mathrm{NaOH}$, under a steady flow of nitrogen to exclude carbon dioxide at $50{ }^{\circ} \mathrm{C}$ and aged for $24 \mathrm{~h}$. The resulting slurry was then filtered and washed several times with hot deionized and degassed water, and dried at $50{ }^{\circ} \mathrm{C}$ in a vacuum oven. The experimental procedure is summarized in Fig. 1.

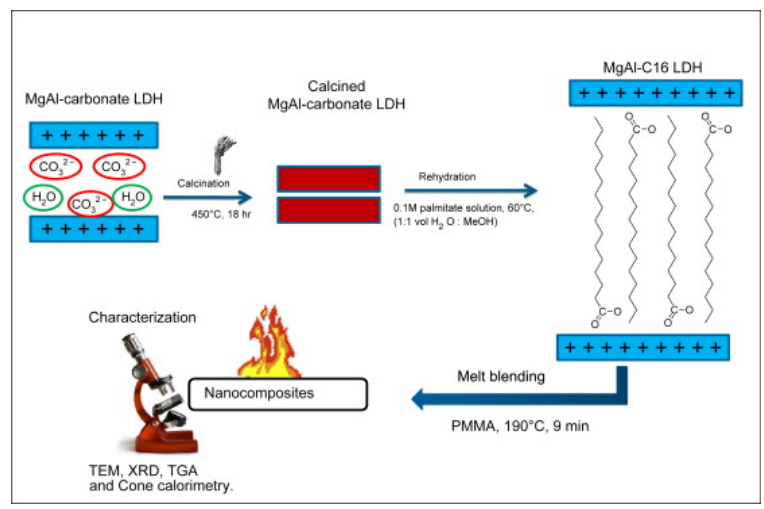

Fig. 1. Intercalation process of palmitate anion in the MgAl-LDH using the rehydration of calcined LDH.

\subsection{Preparation of the poly(methyl methacrylate) composites}

PMMA-LDH composites were prepared via melt blending using established methods $\frac{[23]}{}$; Brabender mixer (temperature $=190^{\circ} \mathrm{C}$, screw speed $=60 \mathrm{rpm}$, and time $=9 \mathrm{~min}$ ). Constitutive proportions of LDHs in the composites were 3 and 10 by weight \% of the MgAl-carbonate, MgAl-nitrate, MgAl-C16 LDHs and calcined material. A sample at the high loading of $20 \%$ by weight of MgAl-C16 LDH was also prepared. A reference sample of pristine PMMA was obtained following the same procedure without any additive. 


\section{Results and discussion}

\subsection{Characterization of MgAl-LDH and its PMMA composites}

\subsubsection{Infrared and X-ray diffraction analysis}

FT-IR spectra for the LDHs are presented in Fig. 2. A broad band in the $3000 \mathrm{~cm}^{-1}$ and $3500 \mathrm{~cm}^{-1}$ region of all the $\mathrm{LDH}$ s originates from the $\mathrm{O}-\mathrm{H}$ stretching from water and the metal layers. The $\mathrm{MgAl}-\mathrm{CO}_{3} \mathrm{LDH}$ spectrum shows a sharp peak at $1365 \mathrm{~cm}^{-1}$ due to the vibration of the carbonate anion. After calcination at $450^{\circ} \mathrm{C}$, the spectrum of calcined LDH show the presence of residual free carbonate at $1412 \mathrm{~cm}^{-1}$. The shift in vibration bands of the carbonate anions to the higher value may be due to change in chemical environment since intercalation imposes steric hindrance on the vibration of carbonate bonds. After rehydration, new peaks appeared: i.e., peaks at $2924 \mathrm{~cm}^{-1}$ and $2836 \mathrm{~cm}^{-1}$, due to the asymmetric and symmetric stretching from $\mathrm{C}-\mathrm{H}$; an $\mathrm{O}-\mathrm{H}$ bending of water at $1641 \mathrm{~cm}^{-1}$ and a band assigned to the carboxylate at $1564 \mathrm{~cm}^{-1}$. The appearance of these new peaks confirmed intercalation of the palmitate anions and the success of the rehydration process.

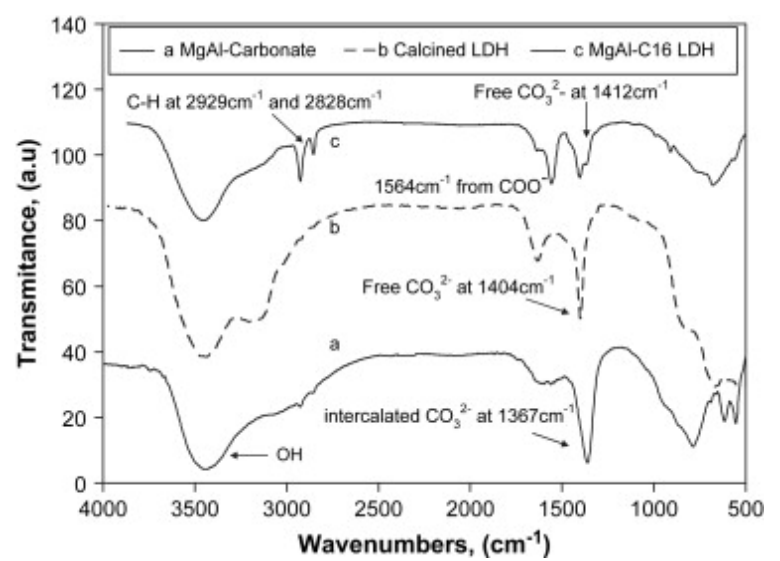

Fig. 2. FT-IR spectra of (a) MgAl-carbonate LDH, (b) Calcined MgAl-carbonate LDH and (c) MgAl-C16 LDH after rehydration. Spectra are offset for clarity.

Fig. 3(a) shows the XRD patterns and d-spacings (d) obtained using the Bragg equation. The MgAlcarbonate and MgAl-C16 LDHs show equidistantly spaced diffraction peaks, characteristic of good layered structure. Upon calcination, the layered structure of $\mathrm{MgAl}$-carbonate is lost due to the decomposition of the carbonate to $\mathrm{CO}_{2}$ and elimination of intralayer water resulting in collapse of the MgAl layers. The XRD of the calcined LDH show no distinct crystalline phase. Reconstruction of the layers via rehydration of the calcined oxides in the presence of palmitate anions led to the formation of wellordered MgAl-C16 LDH with a larger d-spacing of $28.5 \AA$, compared to that of the pristine LDH, $7.6 \AA$. This increase in $d$-spacing confirms the intercalation of the long palmitate anion in the galleries of the $\mathrm{LDH}$. There is no significant difference in the XRD pattern of the MgAl-C16 prepared by anion exchange from the MgAl-nitrate LDH with that prepared from rehydration of the calcined LDH as shown in Fig. 3(b). It is worth noting that the FT-IR of the calcined LDH showed the presence of free residual carbonate anions, but this cannot be crystalline or the XRD pattern of the calcined LDH would have shown it. The XRD pattern and FT-IR spectra of the MgAl-nitrate and MgAl-C16 prepared by anion exchange has been reported elsewhere ${ }^{[4]}$. These show good layered structure and presence of nitrate anion in the galleries of the LDH. 

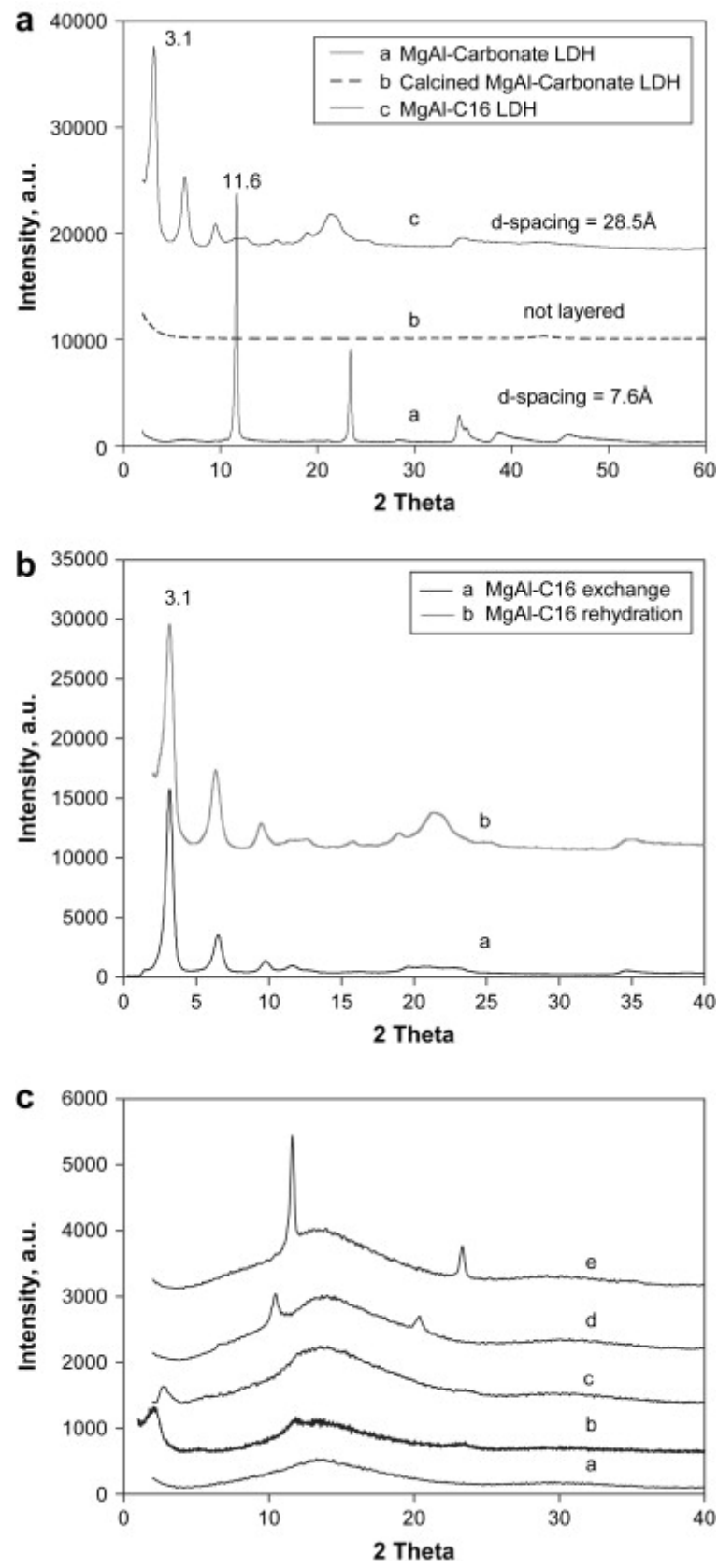

Fig. 3. (a): Powder XRD patterns of (a) MgAl-carbonate LDH, (b) Calcined MgAl-carbonate LDH and (c) MgAl-C16 LDH after rehydration. Fig. 3(b): Powder XRD patterns of (a) MgAl-C16 LDH exchanged from nitrate LDH and, (b) MgAl-C16 LDH obtained from rehydration of calcined LDH Fig. 3(c): XRD patterns for the composites of (a) PMMA + 3\% calcined LDH, (b) PMMA + 3\% MgAl-C16 exchange LDH (c) PMMA + 3\% MgAl-C16 rehydration LDH, (d) PMMA + 3\% MgAl-nitrate LDH (e) PMMA + 3\% MgAl-carbonate LDH.

\subsubsection{XRD and transmission electron microscopy of the composites}

The dispersion of the LDHs was assessed with X-ray diffraction (XRD) and transmission electron microscopy (TEM). In terms of characterizing polymer nanocomposites, XRD is not a stand-alone technique and should be used together with TEM to obtain an assessment of dispersion ${ }^{[24]}$. XRD traces of the composites at 3\% loading of the additives are presented in Fig. 3(c) while the TEM images are shown in Fig. 4. As expected, no diffraction peaks were observed in composites containing calcined LDH, 
since the additive is not a layered material. The PMMA composites with MgAl-C16 LDH prepared using the anion exchange and rehydration methods showed peaks shifted to lower values of $2 \theta, 2.3^{\circ}$ and $2.8^{\circ}$ respectively. Shifting of the peak to lower values of $2 \vartheta$ means an increase in $d$-spacing, indicating that the polymer has entered the gallery and expanded the layers. This system may be described as an intercalated nanocomposite and this in good agreement with reported TEM data ${ }^{[4],}{ }^{[5]}$. With PMMA + MgAl-carbonate and PMMA + MgAl-nitrate LDH composites, the position of the diffraction peaks did not change and peaks are observed at $2 \vartheta$ values of 11.6 and 10.0 , respectively. At low magnification, the TEM images for the composites with the calcined LDH, MgAl-carbonate and MgAlnitrate LDHs show large agglomerated tactoids of poorly dispersed LDH. The high magnification TEM images of the composites with MgAl-nitrate and MgAl-carbonate LDH, presented in Fig. 4(b) and (d), show some layers of LDH. Since no change in the d-spacing was observed in the XRD patterns of these composites, this indicates that the polymer did not enter the galleries of the LDHs. Based on the XRD and TEM data of the PMMA composites with calcined LDH, MgAl-carbonate and MgAl-nitrate, these systems can be best described as microcomposites.

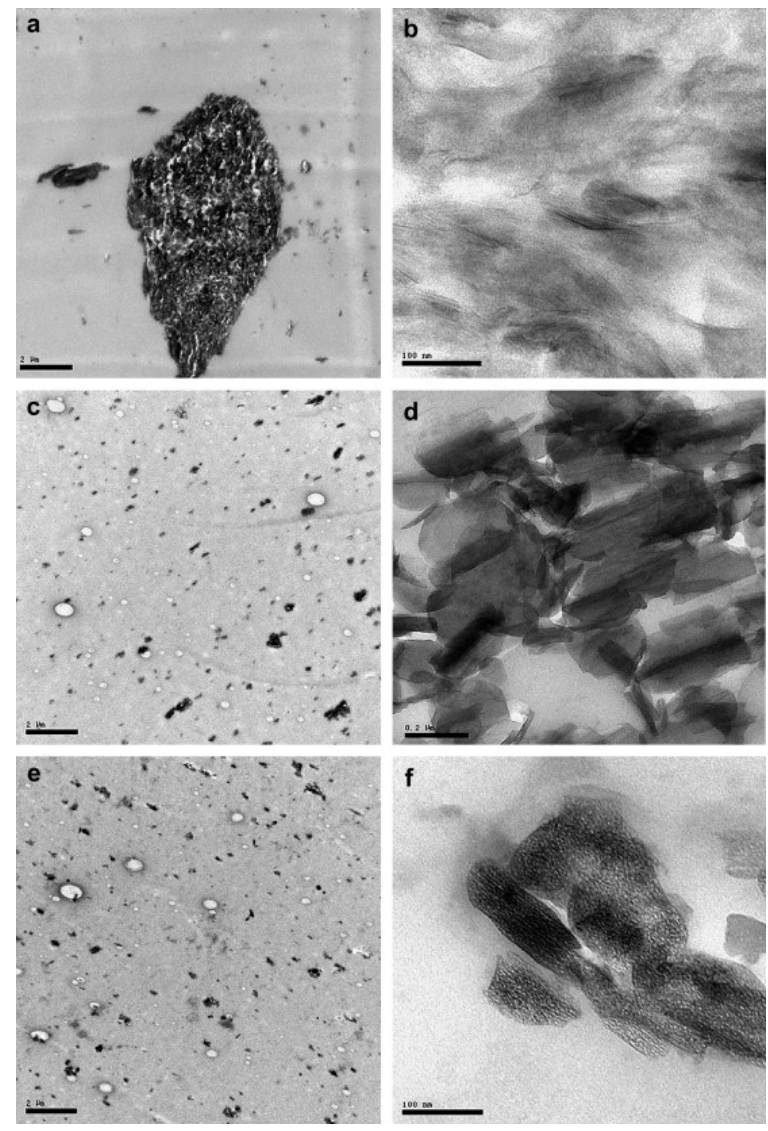

Fig. 4. TEM images at (a) low and (b) high magnification for PMMA + MgAl-nitrate LDH, (c) low and (d) high magnification for PMMA + MgAl-carbonate LDH and (e) low and (f) high magnification for calcined MgAlcarbonate LDH. The scale bars for low and high magnification are indicated on the images.

\subsection{Thermal stability of the MgAl-LDHs and their PMMA composites}

The thermal decomposition of the LDHs is shown in the TGA curves in Fig. 5(a) and the data is summarized in Table 1. The TGA curves for the MgAl-C16 LDHs from rehydration and anion exchange overlay; the thermal degradation pattern of these LDHs is the same; there is no difference in thermal 
stability of the LDHs prepared by rehydration or by anion exchange. As expected, the residue obtained at $600{ }^{\circ} \mathrm{C}$ shows that the smallest amount of residue is obtained with the organically-modified LDH while the highest amount was observed in the calcined LDHs. This is reasonable since the palmitate anions in MgAl-C16 LDH will completely decompose while, with the calcined LDH, only trace amounts of residual carbonate, hydroxyls from metal layers and water adsorbed from atmosphere during cooling after calcination will be lost. Both MgAl-nitrate and MgAl-carbonate LDHs intercalated with the inorganic anions also show an amount of residue significantly higher than the organically-modified LDHs, which is expected since the inorganic anions are of lower molecular weight.
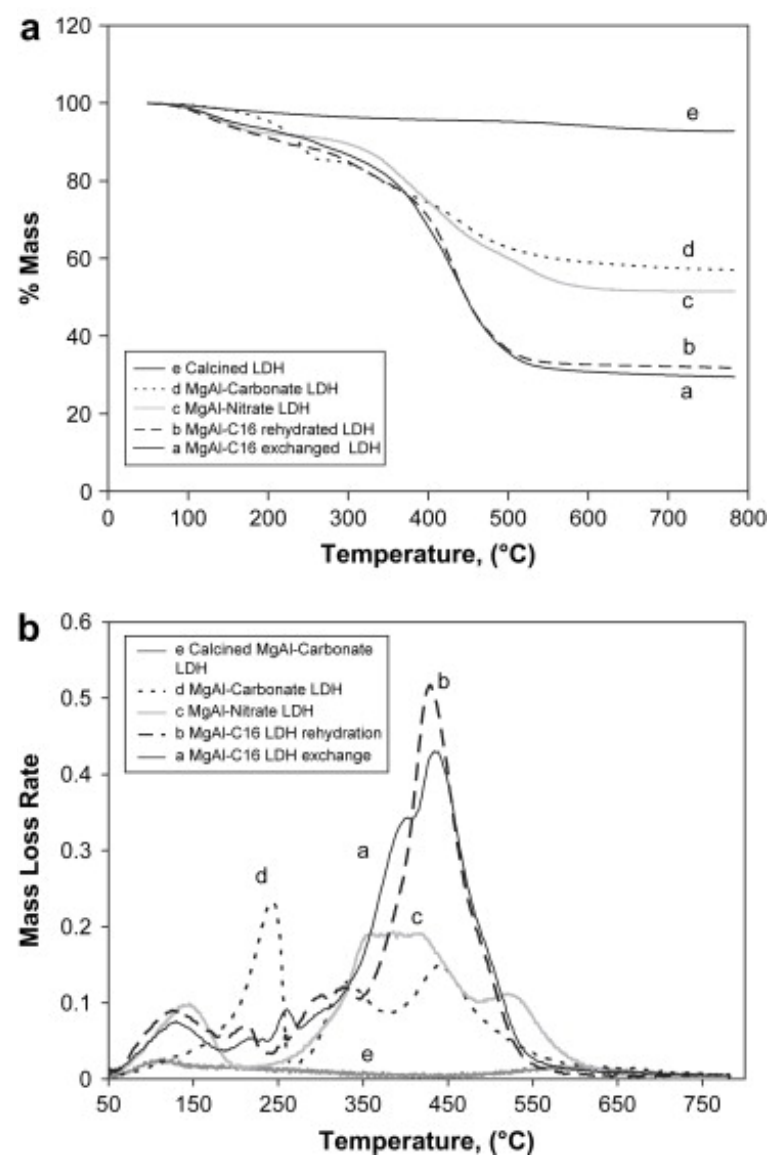

Fig. 5. (a): TGA curves for (a) MgAl-C16 LDH exchanged from nitrate LDH, (b) MgAl-C16 LDH, rehydrated from calcined LDH, (c) MgAl-nitrate LDH from coprecipitation, (d) MgAl-carbonate LDH and (e) Calcined MgAlcarbonate LDH. Fig. 5(b) : TGA curves for (a) MgAl-C16 LDH exchanged from nitrate LDH, (b) MgAl-C16 LDH, rehydrated from calcined LDH, (c) MgAl-nitrate LDH from coprecipitation, (d) MgAl-carbonate LDH and (e) Calcined MgAl-carbonate LDH.

Table 1. TGA data for the LDHs.

\begin{tabular}{|l|l|l|l|}
\hline Formulation & $\boldsymbol{T}_{\mathbf{0 . 1}}\left({ }^{\circ} \mathbf{C}\right)$ & $\boldsymbol{T}_{\mathbf{0 . 5}}\left({ }^{\circ} \mathbf{C}\right)$ & \%Char \\
\hline MgAl-carbonate LDH & 236 & - & 59 \\
\hline Calcined LDH & - & - & 94 \\
\hline MgAl-C16 LDH rehydration & 237 & 447 & 31 \\
\hline MgAl-C16 LDH exchange & 256 & 448 & 33 \\
\hline $\mathrm{MgAl}-\mathrm{NO}_{3} \mathrm{LDH}$ coprecipitation & 290 & - & 52 \\
\hline
\end{tabular}


$T_{0.1}$, temperature at which $10 \%$ mass loss occurs; $T_{0.5}$, temperature at which $50 \%$ mass loss occurs; $\%$ Char, residue at $600{ }^{\circ} \mathrm{C}$.

Table 2. TGA data for the PMMA composites.

\begin{tabular}{|l|l|l|l|l|l|}
\hline Formulation & $\boldsymbol{T}_{\mathbf{0 . 1}}\left({ }^{\circ} \mathbf{C}\right)$ & $\boldsymbol{T}_{\mathbf{0 . 5}}\left({ }^{\circ} \mathbf{C}\right)$ & \%Char & $\boldsymbol{\Delta} \boldsymbol{T}_{\mathbf{0 . 5}}$ & $\boldsymbol{\Delta} \boldsymbol{T}_{\mathbf{0 . 1}}$ \\
\hline PMMA & 277 & 355 & 0 & & \\
\hline PMMA + 3\%MgAl-Carbonate LDH & 288 & 376 & 4 & 21 & 11 \\
\hline PMMA + 10\%MgAl-Carbonate LDH & 290 & 378 & 7 & 23 & 13 \\
\hline PMMA + 3\%Calcined LDH & 284 & 372 & 4 & 17 & 7 \\
\hline PMMA + 10\%Calcined LDH & 292 & 386 & 11 & 31 & 15 \\
\hline PMMA + 3\%MgAl-C16 LDH & 291 & 389 & 3 & 34 & 14 \\
\hline PMMA + 10\%MgAl-C16 LDH & 295 & 394 & 8 & 39 & 18 \\
\hline PMMA + 20\%MgAl-C16 LDH & 296 & 403 & 11 & 48 & 19 \\
\hline PMMA + 3\%MgAl-Nitrate LDH & 287 & 358 & 3 & 3 & 10 \\
\hline PMMA + 10\%MgAl-Nitrate LDH & 289 & 341 & 6 & -14 & 12 \\
\hline
\end{tabular}

$T_{0.1}$, temperature at which $10 \%$ mass loss occurs; $T_{0.5}$, temperature at which $50 \%$ mass loss occurs; $\%$ Char, residue at $600{ }^{\circ} \mathrm{C} ; \Delta T_{0.5}, T_{0.5}$ (composites) minus $T_{0.5}$ (neat PMMA); $\Delta T_{0.1}, T_{0.1}$ (composites) minus $T_{0.1}$ (neat PMMA).

The DTG curves of the LDHs are presented in Fig. 5(b). Thermal degradation of both organically-modified and unmodified LDHs is well understood and proceeds via three or four steps [25], [26], [27], [28], [29]. The first step, below $150^{\circ} \mathrm{C}$, is assigned to the loss of adsorbed water, followed by the loss of intralayer water between 150 and $250{ }^{\circ} \mathrm{C}$. The last two steps, above $250{ }^{\circ} \mathrm{C}$, are due to dehydroxylation and loss of the gallery anions, respectively, and these two steps may overlap. No degradation steps were observed in the calcined LDHs.

Kashiwagi et al. have studied the thermal degradation of PMMA and identified three steps. These steps have been assigned to the presence of head-to-head linkages, end-chain saturation and the major step is due to random scission $\frac{[30]}{}$. As shown in Fig. 6 and Table 2 , the addition of the LDHs and calcined oxides to PMMA resulted in an increase in thermal stability of the composites and does not affect the degradation steps of PMMA. The onset decomposition, $T_{0.1}$, which is the temperature at $10 \%$ mass loss, is significantly increased for all the composites while the mid-point decomposition temperature, $T_{0.5}$, which is the temperature at which $50 \%$ mass is lost, is only increased in composites containing MgAlcarbonate, MgAl-C16 LDHs and calcined LDHs. The MgAl-nitrate LDH shows a thermal destabilization effect as measured by the decrease in the mid-point decomposition temperature. With MMT nanocomposites it has been hypothesized that the increase in the thermal stability is due to both the restricted thermal motion of the polymer chains in the silicate interlayer and the physical interaction of the clay with the polymer ${ }^{[31]}$, [32]. Since a significantly larger thermal stabilization effect is observed with the organically-modified MgAl-C16 LDHs composites, this effect may also be due to the improved physical interaction of the organo-LDHs and polymer or from increased hydrophobicity of organo-LDH that makes it more compatible with the polymer. These TGA results are consistent with previous data from this laboratory ${ }^{[33], ~[34], ~[35] . ~}$ 

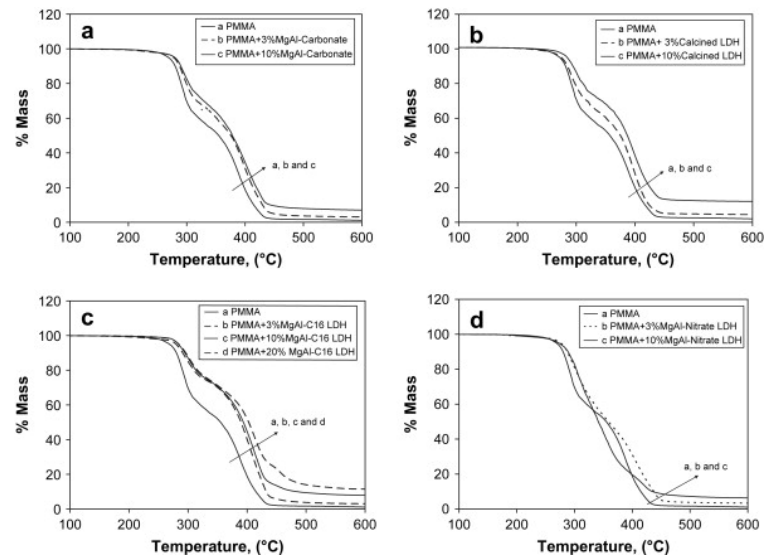

Fig. 6. TGA curves (a) PMMA + MgAl-carbonate LDH, (b) PMMA + Calcined LDH, (c) PMMA + MgAl-C16 LDH, and (d) PMMA + MgAl-nitrate LDH.

\subsection{Flammability behavior of PMMA composites}

The flammability behavior of the composites was studied by cone calorimetry. Important parameters obtained includes the heat release rate, HRR, and especially its peak value, PHRR; volume of smoke released, VOS; total heat released, THR; time to ignition, $t_{\text {ig; }}$ and char yield. The cone calorimeter data is summarized in Table 3 , and plots of HRR versus time are shown in Fig. 7. Previous literature has suggested that, since the MgAl-LDHs resemble the commercial flame retardants alumina trihydrate (ATH) and magnesium hydroxide (MDH), fire retardancy may be attributed to their decomposition which (i) is endothermic and absorbs heat, (ii) releases water and carbon dioxide that cools and dilutes the gases in the pyrolysis zone, and (iii) results in the formation of refractory MgAl-oxides that form an insulating ceramic-like layer that suppresses fuel supply to the flaming zone ${ }^{[36]}$. Therefore, if the formation of the MgAl-oxides is the dominating factor in the fire retardancy mechanism of MgAl-LDH, it would be expected that the composites consisting of calcined oxides with highest inorganic content, followed by the MgAl-carbonate LDHs and MgAl-nitrate LDH as measured by TGA char residue, would result in the best fire properties. If the endothermic decomposition and release of carbon dioxide and water are the dominating factors, then the composites containing MgAl-carbonate and calcined LDHs should give fire properties that are significantly different. In contrast to this, the composites consisting of unmodified MgAl-carbonate and calcined LDH with highest inorganic content gave a similar PHRR while the best PHRR reduction, 51\%, was only observed in organically-modified MgAl-C16 LDH composites with the lowest inorganic content. These observed improved fire properties, which are higher compared to silicate clays $\frac{[37]}{}$, may be explained by nanocomposite formation as a result of excellent dispersion. Radical trapping ${ }^{[38]}$ and a barrier mechanism ${ }^{[16]}$ are the most accepted flame retardant mechanisms for silicate clay nanocomposites and no mechanism has been proposed for the flame retardant mechanism of LDH nanocomposites.

Table 3. Cone calorimetry data for PMMA composites at $50 \mathrm{~kW} / \mathrm{m}^{2}$.

\begin{tabular}{|l|l|l|l|l|l|l|}
\hline Formulation & PHRR & THR & VOS & AMLR & $\boldsymbol{t}_{\text {ig }}$ & $\begin{array}{l}\text { Char } \\
\text { yield }\end{array}$ \\
\hline & $\mathbf{k W / \mathbf { m } ^ { 2 }}$ & $\mathbf{M J} / \mathbf{m}^{\mathbf{2}}$ & $\mathbf{L}$ & $\mathbf{g} / \mathbf{s e c}^{*} \mathbf{m}^{\mathbf{2}}$ & $\mathbf{s e c}$ & $\mathbf{\%}$ \\
\hline PMMA & $1028 \pm 48$ & $82 \pm 2$ & $412 \pm 51$ & $34 \pm 3$ & $14 \pm 1$ & $0 \pm 0$ \\
\hline $\begin{array}{l}\text { PMMA + 3\%MgAl- } \\
\mathrm{NO}_{3} \text { LDH }\end{array}$ & $\begin{array}{l}836 \pm 58 \\
(19)\end{array}$ & $72 \pm 1$ & $334 \pm 4$ & $30 \pm 2$ & $11 \pm 1$ & $5 \pm 1$ \\
\hline
\end{tabular}




\begin{tabular}{|c|c|c|c|c|c|c|}
\hline $\begin{array}{l}\text { PMMA + 10\%MgAl- } \\
\mathrm{NO}_{3} \mathrm{LDH}\end{array}$ & $823 \pm 15(20)$ & $74 \pm 3$ & $358 \pm 31$ & $29 \pm 1$ & $8 \pm 2$ & $12 \pm 2$ \\
\hline $\begin{array}{l}\mathrm{PMMA}+3 \% \mathrm{MgAl}- \\
\mathrm{CO}_{3} \mathrm{LDH}\end{array}$ & $902 \pm 19(12)$ & $77 \pm 1$ & $278 \pm 15$ & $30 \pm 2$ & $12 \pm 1$ & $6 \pm 1$ \\
\hline $\begin{array}{l}\text { PMMA + 10\%MgAl- } \\
\mathrm{CO}_{3} \mathrm{LDH}\end{array}$ & $\begin{array}{l}721 \pm 35 \\
(30)\end{array}$ & $77 \pm 1$ & $349 \pm 61$ & $22 \pm 3$ & $14 \pm 1$ & $14 \pm 1$ \\
\hline $\begin{array}{l}\text { PMMA + 3\%Calcined } \\
\text { LDH }\end{array}$ & $\begin{array}{l}900 \pm 22 \\
(12)\end{array}$ & $77 \pm 1$ & $279 \pm 14$ & $30 \pm 2$ & $12 \pm 2$ & $8 \pm 1$ \\
\hline $\begin{array}{l}\text { PMMA + 10\%Calcined } \\
\text { LDH }\end{array}$ & $\begin{array}{l}704 \pm 12 \\
(31)\end{array}$ & $71 \pm 1$ & $280 \pm 12$ & $34 \pm 2$ & $12 \pm 2$ & $22 \pm 2$ \\
\hline $\begin{array}{l}\text { PMMA + 3\%MgAl-C16 } \\
\text { LDH }\end{array}$ & $782 \pm 4(24)$ & $80 \pm 11$ & $407 \pm 45$ & $27 \pm 3$ & $11 \pm 1$ & $3 \pm 1$ \\
\hline $\begin{array}{l}\text { PMMA + 10\%MgAl-C16 } \\
\text { LDH }\end{array}$ & $\begin{array}{l}504 \pm 13 \\
(51)\end{array}$ & $72 \pm 4$ & $435 \pm 85$ & $16 \pm 1$ & $14 \pm 1$ & $10 \pm 0$ \\
\hline $\begin{array}{l}\text { PMMA + 20\%MgAl-C16 } \\
\text { LDH }\end{array}$ & $329 \pm 2(68)$ & $67 \pm 1$ & $1385 \pm 220$ & $7 \pm 2$ & $16 \pm 2$ & $22 \pm 1$ \\
\hline
\end{tabular}

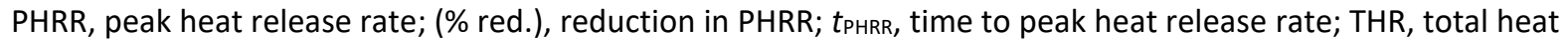
release; VOS, Volume of Smoke released; AMLR, average mass loss rate; $t_{\text {ign, }}$ time-to-ignition.
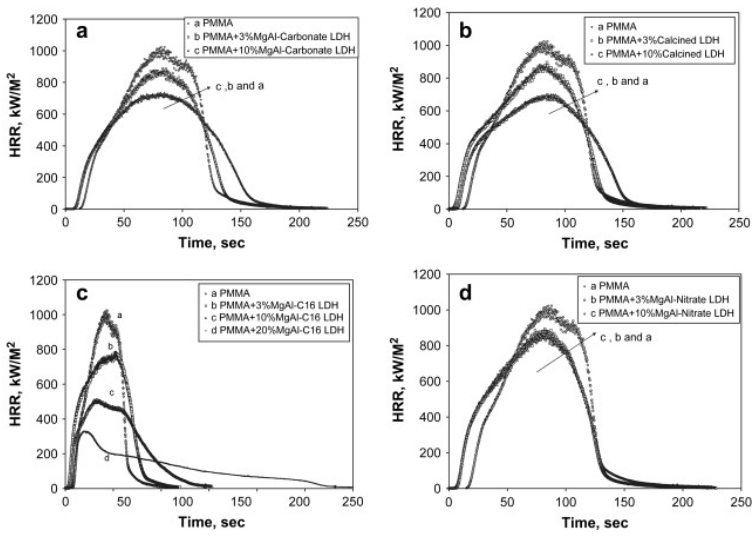

Fig. 7. Heat release rate curves for (a) PMMA + MgAl-carbonate LDH, (b) PMMA + calcined LDH, (c) PMMA + MgAl-C16 LDH, and (d) PMMA + MgAl-nitrate LDH.

It has also been shown that MMT nanocomposites give reduced peak heat release rate while microcomposites do not $\frac{[39]}{}$. With these LDH systems the best reduction in PHRR was observed with the well dispersed PMMA + MgAl-C16 LDH nanocomposites and the lowest reduction with poorly dispersed unmodified PMMA + MgAl-carbonate and PMMA + MgAl-nitrate microcomposites. At $10 \%$ additive loading the volume of smoke remains unchanged while it is significantly reduced when the calcined material is used. For all the composites the total heat released, THR, and the time to ignition also remain unchanged. The fire properties of the composites containing MgAl-C16 LDH prepared by rehydration are comparable to those observed with the MgAl-C16 LDH prepared from anion exchange ${ }^{[4]}$. The route used to produce the organically-modified LDH has no effect on its performance.

Photographs of the chars after cone calorimetry are presented in Fig. 8. The char from MgAl-C16 is expanded and sponge-like and does not cover the sample holder, while that for the calcined LDH was a fine soft powder covering the entire aluminum sample holder. The highest char yield was obtained with the calcined LDH, which is expected due to its high inorganic content, as observed in TGA. There is no 
significant difference in the char yield observed with the MgAl-C16, MgAl-carbonate and MgAl-nitrate LDHs. XRD analysis of the char shows that the oxides formed during cone calorimetry exhibit poor crystallinity and may be amorphous, as shown in Fig. 9(a). Calcination of the char at $1000^{\circ} \mathrm{C}$ for $24 \mathrm{~h}$ led to the formation of $\mathrm{MgO}$ and $\mathrm{MgAl}_{2} \mathrm{O}_{4}$ spinel phases. These phases have been indexed ${ }^{[40]}$ and the diffraction traces are shown in Fig. 9(b). There is no difference in the XRD patterns of the calcined chars obtained from the composites containing MgAl-nitrate, MgAl-C16, MgAl-carbonate and calcined oxides; indexing of these phases is in agreement to that reported in the literature $\frac{[41]}{\text {. }}$
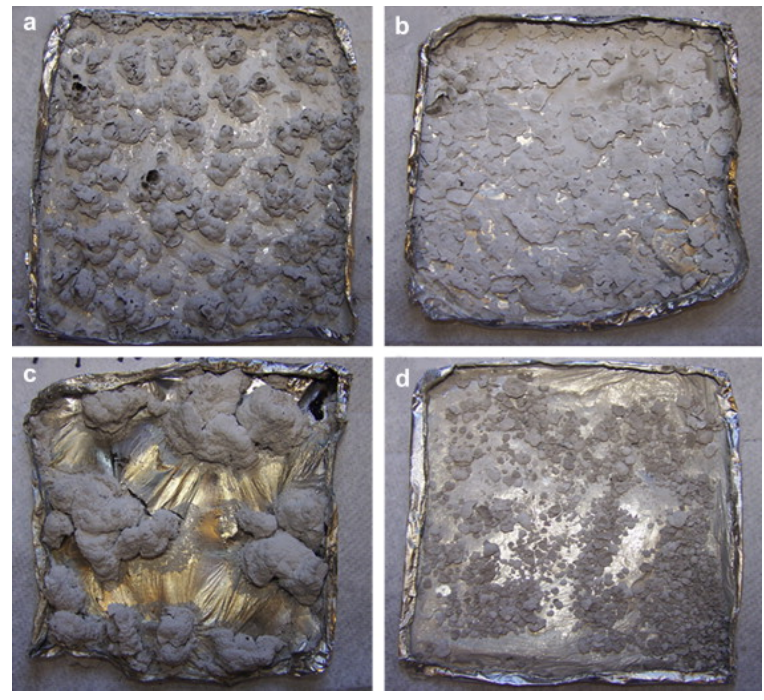

Fig. 8. Photographs of residual char from (a) PMMA + MgAl-carbonate LDH, (b) PMMA + calcined LDH, (c) PMMA + MgAl-C16 LDH, and (d) PMMA + MgAl-nitrate LDH formulations following cone calorimetry at a heat flux of $50 \mathrm{~kW} / \mathrm{m}^{2}$. 

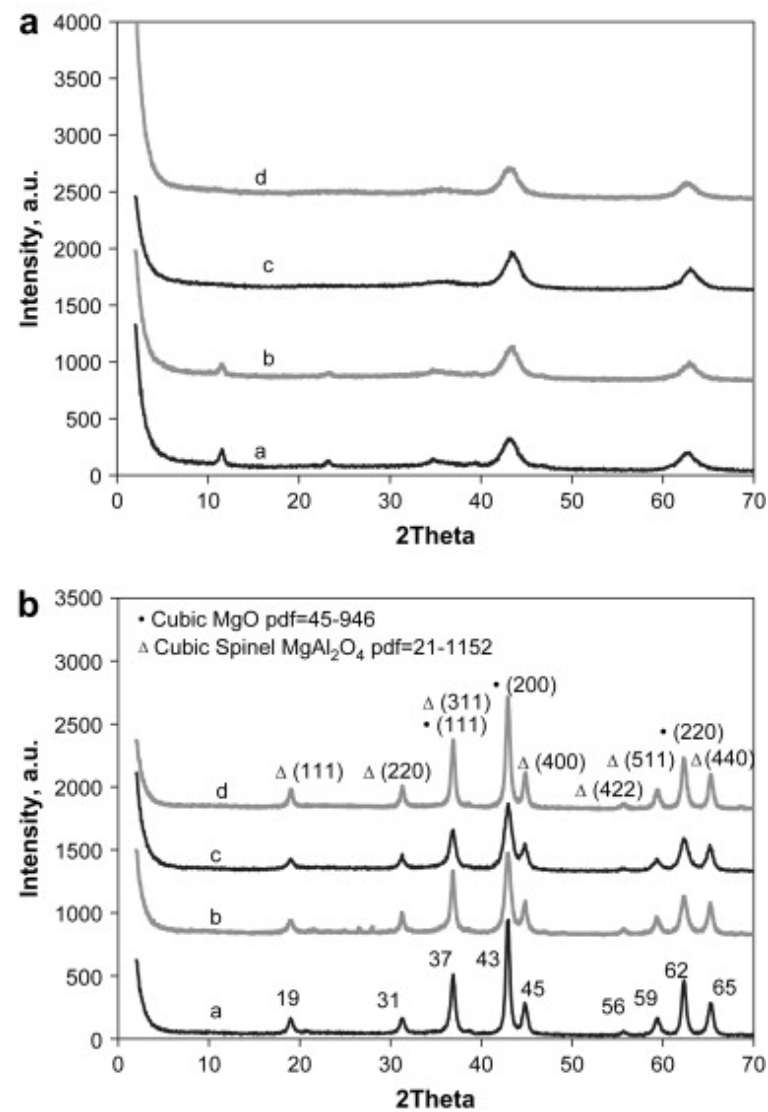

Fig. 9. (a): XRD of residual char for; (a) PMMA + MgAl-carbonate LDH, (b) PMMA + calcined LDH, (c) PMMA + MgAl-C16 LDH, and (d) PMMA + MgAl-nitrate LDH formulations following cone calorimetry at a heat flux of $50 \mathrm{~kW} / \mathrm{m}^{2}$. Fig. 9(b): XRD of residual char for; (a) PMMA + MgAl-carbonate LDH, (b) PMMA + calcined LDH, (c) PMMA + MgAl-C16 LDH, and (d) PMMA + MgAl-nitrate LDH formulations following cone calorimetry test at a heat flux of $50 \mathrm{~kW} / \mathrm{m}^{2}$ and calcination at $1000^{\circ} \mathrm{C}$.

\section{Conclusions}

Organic modification of hydrotalcite was achieved by rehydration of the calcined LDH. PMMA composites consisting of MgAl-nitrate, MgAl-carbonate, MgAl-C16 LDHs and calcined LDH were successfully prepared using melt blending. These composites showed improved thermal stability. The largest thermal stabilization effect was observed with the organically-modified MgAl-C16 LDH composites. TEM and XRD reveal that the composites obtained using MgAl-carbonate, MgAl-nitrate and calcined LDH were microcomposites while those obtained from organically-modified LDH were nanocomposites. Fire properties studied by the cone calorimeter show that the peak heat release rate, PHHR, is significantly reduced, $51 \%$, in composites consisting of organically-modified MgAl-C16 LDH while it was reduced by about $30 \%$ in unmodified MgAl-carbonate, MgAl-nitrate and calcined LDH composites. There is no significant difference in the fire properties of PMMA composites with MgAl-C16 LDH obtained from rehydration or anion exchange. Organic modification of the MgAl-carbonate LDH improves both the fire and thermal properties of PMMA. Improved physical interaction and good nanodispersion may be the reason for the observed enhanced thermal and fire properties. Promising developments for use of LDHs in flame retardant formulations are expected in future applications. 


\section{Acknowledgements}

The authors gratefully thank Dr Jeanne Hossenlopp for helpful discussions. Partial support of the work was provided by the US Department of Commerce, National Institute of Science and Technology (NIST), Grant 60NANB6D6018.

\section{References}

[1] Vaccari A. Preparation and catalytic properties of anionic and cationic clays. Catal Today 1998;41:5371.

[2] Prasanna SV, Anantha Padmanabha Rao R, Vishnu Kamath P. Layered double hydroxides as potential chromate scavengers. J Colloid Interface Sci 2006;304:292-9.

[3] Nyambo C, Kandare E, Wang D, Wilkie C. Flame-retarded polystyrene: investigating chemical interactions between ammonium polyphosphate and MgAl layered double hydroxide. Polym Degrad Stab 2008;93:1656-63.

[4] Nyambo C, Songtipya P, Manias E, Jimenez-Gasco M, Wilkie CA. Effect of MgAl-layered double hydroxide exchanged with linear alkyl carboxylates on fire retardancy of PMMA and PS. J Mater Chem 2008;18:4827-38.

[5] Nyambo C, Wang D, Wilkie CA. Will layered double hydroxides give nanocomposites with polar or non polar polymers? Polym Adv Technol 2008. doi:10.1002/pat1272.

[6] Manzi-Nshuti C, Wang D, Hossenlopp JM, Wilkie CA. Aluminum-containing layered double hydroxides: the thermal, mechanical, and fire properties of (nano) composites of poly(methyl methacrylate). J Mater Chem 2008;18:3091-102.

[7] Van der Ven L, van Gemert MLM, Batenburg LF, Keern JJ, Gielgens LH, Koster TPM, et al. On the action of hydrotalcite-like clay materials as stabilizers in polyvinylchloride. Appl Clay Sci 2000;17:25-34.

[8] Del Hoyo C. Layered double hydroxides and human health: an overview. Appl Clay Sci 2007;36:10321.

[9] Ping Z, Lu GQ. Layered double hydroxide nanomaterials as potential cellular drug delivery agents. Pure Appl Chem 2006;78:1771-9.

[10] Newman SP, Jones W. Synthesis, characterization and applications of layered double hydroxides containing organic guests. New J Chem 1998;2:105-15.

[11] Evans DG, Duan X. Preparation of layered double hydroxides and their applications as additives in polymers, as precursors to magnetic materials and in biology and medicine. Chem Commun 2006;5:485-96.

[12] Carlino $S$. The intercalation of carboxylic acids into layered double hydroxides: a critical evaluation and review of the different methods. Solid State lonics 1997;98:73-84.

[13] Kooli F, Depege C, Ennaqadi A, De Roy A, Besse JP. Rehydration of Zn-Al layered double hydroxides. Clays Clay Miner 1997;45:92-8.

[14] Chibwe K, Jones W. Intercalation of organic and inorganic anions into layered double hydroxides. J Chem Soc Chem Commun 1989;14:926-7.

[15] Rocha J, Del Arco M, Rives V, Ulibarri MA. Reconstruction of layered double hydroxides from calcined precursors: a powder XRD and 27AI MAS NMR study. J Mater Chem 1999;9:2499-503.

[16] Gilman WJ, Jackson CL, Morgan AB, Harris R, Manias E, Ginnelis EP, et al. Flammability properties of polymer - layered silicate nanocomposites. Polypropylene and polystyrene nanocomposites.

Chem Mater 2000;12:1866-73; Chen K, Wilkie CA, Vyazovkin S. Revealing nano-confinement in 
degradation and relaxation studies of two structurally different polystyrene-clay systems. $J$ Phys Chem B 2007;111:12685-92; Costache MC, Heidecker MJ, Manias E, Camino G, Frache A, Beyer $G$, et al. The Influence of carbon nanotubes, organically modified montmorillonites and layered double hydroxides on the thermal degradation and fire retardancy o polyethylene, ethylenevinyl acetate copolymer polystyrene. Polymer 2007;48:6532-45.

[17] Zhu J, Morgan AB, Lamelas FJ, Wilkie CA. Fire properties of polystyrene-clay nanocomposites. Chem Mater 2001;13:3774-80.

[18] Alexandre M, Dubois P. Polymer layered silicate nanocomposites: preparation, properties and uses of new class of materials. Mater Sci Eng 2000; R28:1-63.

[19] Zhang J, Manias E, Wilkie CA. Polymerically modified layered silicates: an effective route to nanocomposites. J Nanosci Nanotechnol 2008;8:1597-615.

[20] Gilman JW. Flammability and thermal stability studies of polymer layeredsilicate (clay) nanocomposites. Appl Clay Sci 1999;15:31-49.

[21] Zhang J, Jiang DD, Wilkie CA. Polyethylene and polypropylene nanocomposites based upon an oligomerically modified clay. Thermochimica Acta 2005;430:107-13.

[22] Meyn M, Benecke K, Lagally G. Anion-exchange reactions of layered double hydroxides. Inorg Chem 1990;29:5201-7.

[23] Wang D, Zhu J, Yao Q, Wilkie CA. A comparison of various methods for the preparation of polystyrene and poly(methyl methacrylate) clay nanocomposites. Chem Mater 2002;14:383743.

[24] Morgan AG, Gilman JW. Characterization of polymer layered silicate (clay) nanocomposites by transmission electron microscopy and X-ray diffraction: a comparative study. J Appl Polym Sci 2003;87:1329-38.

[25] Yang W, Kim Y, Liu PKT, Sahimi M, Tsotsis TT. A study by in situ techniques of the thermal evolution of the structure of Mg-Al-CO3 layered double hydroxide. Chem Eng Sci 2002;57:2945-53.

[26] Jakupca M, Dutta PK. Thermal and spectroscopic analysis of a fatty acidlayered double-metal hydroxide and its application as a chromatographic stationary phase. Chem Mater 1995;7:98994.

[27] Pesic L, Salipurovic S, Markovic V, Vucelic D, Kagunya W, Jones W. Thermal characteristics of a synthetic hydrotalcite-like material. J Mater Chem 1992;2:1069-73.

[28] Miyata S. Physico-chemical properties of synthetic hydrotalcite in relation to compositions. Clays Clay Minerals. 1980;28:50-6.

[29] Vincente R. Study of layered double hydroxides by thermal methods. In: Layered double hydroxides; present and future. Nova Science Publisher; 2001. p. 115-37.

[30] Kashiwagi T, Inaba A, Brown EJ. Effects of weak linkages on the thermal and oxidative degradation of poly(methyl methacrylate). Macromolecules 1986;19:2160-8.

[31] Blumstein A. Polymerization of adsorbed monolayers. I. Preparation of the clay-polymer complex. J Polym Sci Part A 1965;3:2653-4.

[32] Blumstein A. Polymerization of adsorbed monolayers. II. Thermal degradation of the inserted polymer. J Polym Sci Part A 1965;3:2665-73.

[33] Zhu J, Start P, Mauritz KA, Wilkie CA. Thermal stability and flame retardancy of poly(methyl methacrylate) - clay nanocomposites. Polym Degrad Stab 2002;77:253-8. 
[34] Costache MC, Wang D, Heidecker MJ, Manias E, Wilkie CA. Thermal degradation of poly(methyl methacrylate) nanocomposites with montmorillonite, layered double hydroxides and carbon nanotubes. Polym Adv Technol 2006;17:272-80.

[35] Jash P, Wilkie CA. Effects of surfactants on the thermal and fire properties of poly (methyl methacrylate)/clay nanocomposites. Polym Degrad Stab 2005;88:401-6.

[36] Camino G, Maffezzoli A, Braglia M, De Lazzaro M, Zammarano M. Effect of hydroxides and hydroxycarbonate structure on fire retardant effectiveness and mechanical properties in ethylene-vinyl acetate copolymer. Polym Degrad Stab 2001;74:457-64.

[37] Zammarano M, Franceschi M, Bellayer S, Gilman JW, Meriani S. Preparation and flame resistance properties of revolutionary self-extinguishing epoxy nanocomposites based on layered double hydroxides. Polymer 2005;46: 9314-28.

[38] Zhu J, Uhl FM, Morgan AB, Wilkie CA. Studies on mechanism by which the formation of nanocomposites enhances thermal stability. Chem Mater 2001;13:4649-54.

[39] Zanetti M, Camino G, Canavese D, Morgan AB, Lamelas FL, Wilkie CA. Fire retardant halogenantimony-clay synergism in polypropylene layered silicate nanocomposites. Chem Mater 2002;14:189-93.

[40] Powder Diffraction File Alphabetical Indexs, Inorganic phases, JCPDS, International Center for Diffraction Data, Swartmore, PA, 1999.

[41] Labajos FM, Rives V, Ulibarri MA. Effects of hydrothermal and thermal treatments on the physicochemical properties of MgAl hydrotalcite-like materials. J Mater Sci 1992;27:1546-52. 